\title{
A Marfan Syndrome-Like Phenotype Caused by a Neocentromeric Supernumerary Ring Chromosome 15
}

\author{
Shane C. Quinonez, ${ }^{1,2 *}$ Thomas D. Gelehrter, ${ }^{2,3}$ and Wendy R. Uhlmann ${ }^{2,3}$ \\ ${ }^{1}$ Department of Pediatrics and Communicable Diseases, University of Michigan Medical School, Ann Arbor, Michigan \\ ${ }^{2}$ Department of Internal Medicine, University of Michigan, Ann Arbor, Michigan \\ ${ }^{3}$ Department of Human Genetics, University of Michigan, Ann Arbor, Michigan
}

Manuscript Received: 23 December 2015; Manuscript Accepted: 26 September 2016

Small supernumerary marker chromosomes (sSMC) are abnormal chromosomes that cannot be characterized by standard banding cytogenetic techniques. A minority of sSMC contain a neocentromere, which is an ectopic centromere lacking the characteristic alpha-satellite DNA. The phenotypic manifestations of sSMC and neocentromeric sSMC are variable and range from severe intellectual disability and multiple congenital anomalies to a normal phenotype. Here we report a patient with a diagnosis of Marfan syndrome and infertility found to have an abnormal karyotype consisting of a chromosome 15 deletion and a ring-type sSMC likely stabilized by a neocentromere derived via a mechanism initially described by Barbara McClintock in 1938. Analysis of the sSMC identified that it contained the deleted chromosome 15 material and also one copy of FBN1, the gene responsible for Marfan syndrome. We propose that the patient's diagnosis arose from disruption of the FBN1 allele on the sSMC. To date, a total of 29 patients have been reported with an SSMC derived from a chromosomal deletion. We review these cases with a specific focus on the resultant phenotypes and note significant difference between this class of sSMC and other types of sSMC. Through this review we also identified a patient with a clinical diagnosis of neurofibromatosis type 1 who lacked a family history of the condition but was found to have a chromosome 17-derived SSMC that likely contained NF1 and caused the patient's disorder. We also review the genetic counseling implications and recommendations for a patient or family harboring an sSMC. () 2016 Wiley Periodicals, Inc.

Key words: Marfan syndrome; small supernumerary marker chromosome (sSMC); neocentromere; McClintock mechanism; infertility; genetic counseling

\section{INTRODUCTION}

Small supernumerary marker chromosomes (sSMC) are structurally abnormal chromosomes that cannot be identified or characterized unambiguously by conventional banding cytogenetic techniques [Liehr and Weise, 2007]. sSMC are estimated to occur
How to Cite this Article: Quinonez SC, Gelehrter TD, Uhlmann WR. 2017. A Marfan syndrome-like phenotype caused by a neocentromeric supernumerary ring chromosome 15.

Am J Med Genet Part A 173A:268-273.

in 3 out of every 10,000 births and have variable phenotypic consequences depending on the genomic regions involved [Liehr and Weise, 2007]. Phenotypes can range from retained fertility and normal intellect to severe intellectual disability and multiple congenital anomalies [Liehr and Weise, 2007]. sSMC most commonly arise from acrocentric chromosomes with approximately $40 \%$ of known sSMC involving chromosome 15 [Liehr, 2016]. A minority of reported sSMC are those containing a neocentrome, which is an ectopic centromere that lacks typically characteristic alpha-satellite DNA and rescues an acentric chromosomal fragment [Marshall et al., 2008]. Neocentromeres bind all known essential centromere proteins and therefore behave like normal centromeres in mitosis and meiosis [Marshall et al., 2008].

Initially discovered in 1993, neocentromeres are most commonly found on inverted duplicated marker chromosomes causing an individual to be tetrasomic for the region of duplication or trisomic if the sSMC is accompanied by a deleted chromosomal complement [Voullaire et al., 1993; Marshall et al., 2008]. Their formation is not completely understood though it has been suggested they may arise from aberrant CENP-A incorporation and/or a chromosomal rearrangement that induces an epigenetic change

${ }^{*}$ Correspondence to:

Shane C. Quinonez, Department of Pediatrics and Communicable Diseases, University of Michigan Medical School, D5240 Medical Professional Bldg, 1500 E. Medical Center Drive, Ann Arbor, MI 48109. E-mail: squinon@med.umich.edu

Article first published online in Wiley Online Library

(wileyonlinelibrary.com): 14 October 2016

DOI 10.1002/ajmg.a.38000 
in the chromatin following DNA repair [Marshall et al., 2008]. In approximately $14 \%$ of neocentromere cases, the neocentromere is associated with a chromosomal deletion and the subsequent formation of a ring chromosome containing the deleted chromosomal material and a neocentromere, resulting in an apparently balanced karyotype [Marshall et al., 2008]. Barbara McClintock initially described the suspected mechanism for the formation of this type of karyotype in 1938 through the study of maize [McClintock, 1938]. She proposed their formation through centromere misdivision when one chromosomal break occurs within one chromosome's centromeric alpha-satellite DNA and a second break occurs in one arm of the chromosome. This results in two centromeres and an apparently balanced karyotype with a partially deleted chromosome and a complementary ring chromosome [McClintock, 1938].

Marfan syndrome (MS; OMIM \#154700) is a well described autosomal dominant connective tissue disorder whose major clinical features include disproportionate long bone overgrowth, aortic root aneurysms, and ectopia lentis [Loeys et al., 2010]. Based on the revised Ghent nosology, the diagnosis of MS relies on a combination of clinical features and molecular testing but can be made exclusively on clinical grounds [Loeys et al., 2010]. In 1991 FBN1, located at 15q21.1 and encoding for fibrillin-1, was identified as the gene responsible for Marfan syndrome [Dietz et al., 1991]. Subsequently, multiple types of pathogenic variants have been identified with disease caused by suspected dominant-negative activity but with haploinsufficency also contributing to disease [Dietz et al., 1993; Eldadah et al., 1995; Judge et al., 2004; Faivre et al., 2007].

Here, we describe the clinical presentation, diagnosis, and cytogenetic workup of an infertile adult male with Marfan syndrome found to have a ring-type sSMC containing both a neocentromere and chromosomal material derived from an interstitial deletion of chromosome 15. A review of the phenotype and karyotype of all postnatal patients reported with sSMC derived from the suspected McClintock-mechanism was also performed.

\section{RESULTS}

\section{Patient Description}

The 34-year-old male patient was referred to the University of Michigan Medical Genetics Clinic for counseling after an abnormal chromosomal constitution was identified on a peripheral blood karyotype. He was clinically diagnosed with Marfan syndrome at age 14 . His medical history consisted of aortic root dilation of $4.7 \mathrm{~cm}$ (Z-score: 5.28 ) and mitral valve prolapse with moderatesevere mitral regurgitation. These abnormalities were previously corrected surgically at 26 years of age via valve-sparing aortic root surgery with mitral valve repair. Additional medical complications included a history of pectus excavatum that was surgically corrected at 5 years of age and the subsequent development of pectus carinatum. The patient also had a history of myopia but with no ectopia lentis. His family history was negative for Marfan syndrome and for similar features. All of the patient's siblings reportedly had normal echocardiograms.

On physical examination his upper segment to lower segment ratio and arm span to height ratio were 0.93 and 0.99 , respectively (normal for mixed European ancestry). His head was normally shaped with level palpebral fissures and no enophthalmos. He exhibited malar hypoplasia but with no retrognathia. No ectopia lentis was visible in the office; glasses were worn for myopia. He reported having a normal dilated ophthalmology exam 1 to 2 years prior and planned to be seen for follow-up. He had arachnodactyly and a positive wrist and thumb sign. A sternotomy scar, a loud systolic murmur and pectus carinatum were also present. Review of his physical examination and past history provided a systemic score of 8 [wrist and thumb sign (3), pectus carinatum (2), pectus excavatum (1), myopia (1), and mitral valve prolapse (1) and a Beighton score of 3/9 with hypermobile bilateral fifth fingers and right knee]. Pertinent negative findings included an absence of the following findings: bifid uvula, cleft palate, hypertelorism, clubfoot, craniosynostosis, abnormal skin, joint abnormalities, joint hypermobility (Beighton score of 3/9), and levido reticularis. Based on his aortic root size (Z-score: 5.28 ) and his systemic score $>7$, his clinical diagnosis of Marfan syndrome was confirmed during his clinic visit.

As a result of failure to conceive, a fertility workup revealed the presence of azoospermia in the patient. A peripheral blood karyotype was performed and showed a non-mosaic abnormal chromosomal constitution; 47,XY,del(15)(q11.1q21.1), $+\mathrm{r}(15)(\mathrm{q} 11.1 \mathrm{q} 21.1)$ (Fig. 1). Metaphase FISH analysis showed that the sSMC hybridized with a probe that targets $15 \mathrm{q} 11.2$ while the chromosome 15 harboring a deletion lacked a hybridization signal. The sSMC showed no hybridization with a probe that targets the alpha-satellite DNA of chromosome 15, suggesting the presence of a neocentromere. Additionally, a probe that hybridizes to $15 \mathrm{q} 12.1$ within the $F B N 1$ gene was used and showed two signals, one on the normal chromosome 15 and one on the sSMC. The karyotype included a combination of an interstitial deletion of chromosome 15 and an sSMC composed of the deleted chromosome 15 material. Alternatively, a very small amount of alphoid DNA may have been present but failed to hybridize with the alpha-satellite specific FISH probe.

The patient was provided with genetic counseling regarding his karyotypic abnormalities in the setting of his azoospermia and Marfan syndrome (see discussion section for additional general information provided about reproductive outcomes). He was counseled that given the diagnosis of Marfan syndrome and a chromosome 15 abnormality that encompasses the FBN1 gene, our suspicion is that the FBN1 Locus on the ring chromosome is in some way disrupted. Possible explanations provided included: (i) the translocation has specifically occurred within the FBN1 gene, thereby disrupting that specific copy; (ii) the FBN1 gene though intact, is expressed at a decreased level as a result of the ring formation; (iii) a specific segment of FBN1 has been deleted due to the translocation, and resulted in a nonfunctional copy and; (iv) the unlikely possibility that a point mutation in one of the two intact genes could cause a loss-of-function, causing Marfan syndrome.

The patient was counseled that as best we can tell, his deletion and subsequent ring formation is balanced, therefore not leaving him haploinsufficient for a number of genes, but presumably has resulted in his having Marfan syndrome and azoospermia. To further characterize his clinical diagnosis of Marfan syndrome and his cytogenetic 


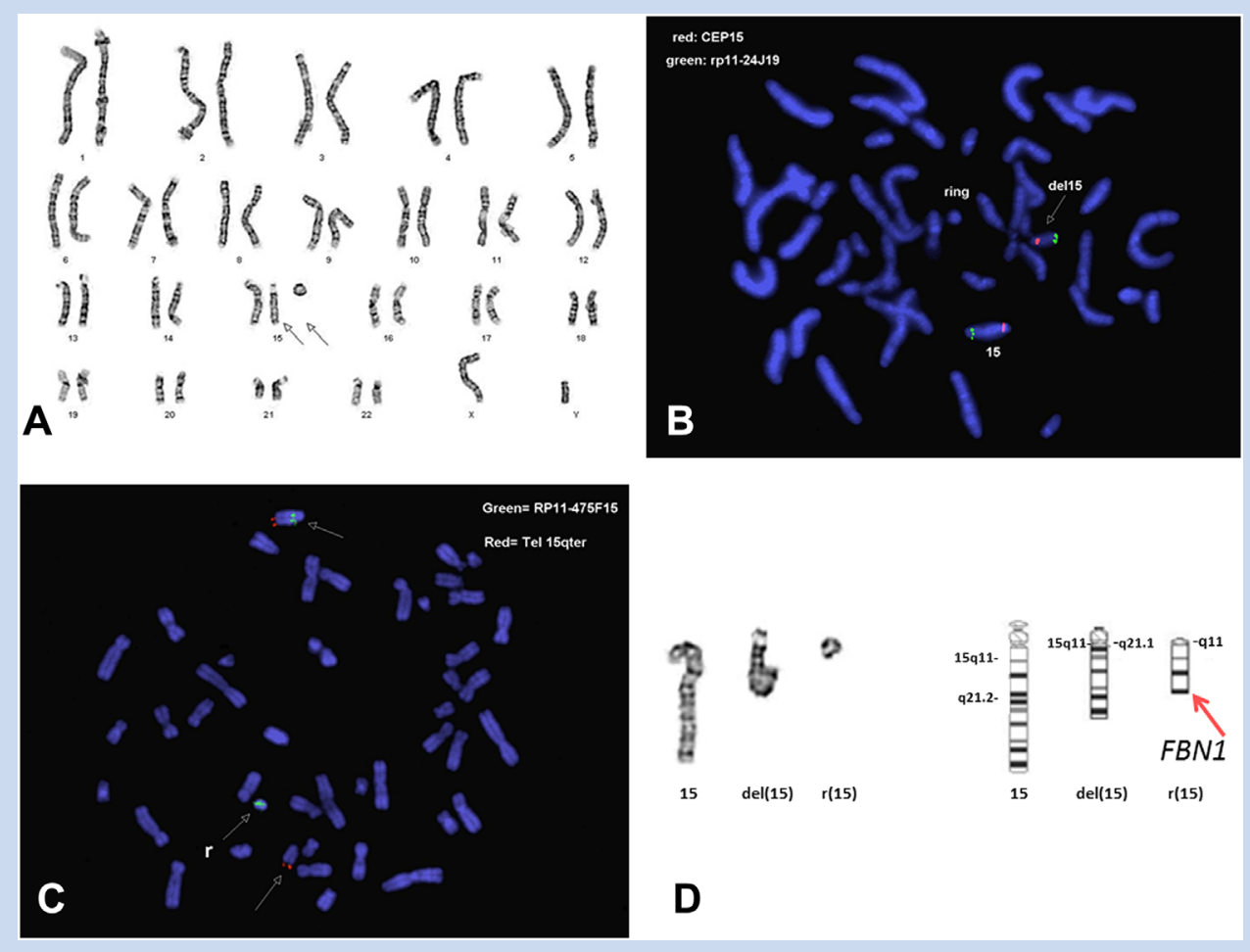

FIG. 1. Cytogenetic results. A: Peripheral karyotype denoted as 47,XY,del[15][q11.1q21.1], $+r[15]$ (q11.1q21.1]. The arrows are pointing out the abnormal chromosome 15 and the SMC. B: Metaphase FISH analysis showing normal hybridization of the normal chromosome 15 with a centromeric chromosome 15 probe (CEP15) and a probe that hybridizes with 15q26.1 (RP11-24J19). The SMC lacks hybridization with the centromeric chromosome 15 probe suggesting the presence of a neocentromere given the SMC material is derived from chromosome 15. C: Metaphase FISH analysis showing at least part of the FBN1 gene from the partially deleted chromosome 15 is on the SMC. The green RP11-475F15 probe [BlueGnome, UK] hybridizes to 15q21.1 [chr15:48,772,344-48,869,180; hg19] within the FBN1 gene. D: Ideogram of both copies of the patient's chromosome 15 and the SMC with the suspected location of the FBN1 gene denoted. [Color figure can be viewed at wileyonlinelibrary.com].

abnormality, FBN1 sequencing and deletion/duplication analysis and chromosome microarray analysis was offered but declined by the patient.

\section{DISCUSSION}

To our knowledge, the patient presented here represents the first and only case of an interstitial deletion of chromosome 15 with a resultant ring-type sSMC stabilized by a neocentromere. The patient also carries a clinical diagnosis of Marfan syndrome based on the presence of a dilated aortic root and a positive systemic score. Interestingly, the ring chromosome was formed from a deletion on chromosome 15 with a distal breakpoint at approximately 15q21.1, the same chromosomal band where FBN1 Lies. Further, FISH analysis showed that at least part of FBN1 was on the sSMC. While further workup was not possible due to patient preference, it is likely that the FBN1 allele on the ring chromosome was disrupted and therefore caused the patient's Marfan syndrome. FBN1 sequencing and/or FNB1 deletion/duplication testing would have provided necessary additional information to further support or disprove this hypothesis. As there is considerable phenotypic overlap with Loeys-Dietz syndrome, molecular testing of TGFBR1,
TGFBR2, SMAD3, and TGFB2 would have been considered if FBN1 testing was normal.

Of all sSMC, ring types represent approximately $10 \%$, while sSMC containing neocentromeres account for only 2\% [Marshall et al., 2008; Liehr, 2016]. Those ring-type sSMC that contain genomic material derived from a chromosomal interstitial deletion and harboring a neocentromere are exceedingly rare [Baldwin et al., 2008; Liehr, 2016].

A total of 29 postnatal patients have been reported with an sSMC derived by the suspected McClintock mechanism that yielded an apparently balanced karyotype (Table I). Review of these patients reveals a highly variable phenotype that includes normal individuals with retained fertility, patients with isolated infertility, and patients with multiple congenital anomalies and severe intellectual disability. Our patient presented with infertility in the form of azoospermia. Fertility problems are a known complication of chromosomal aberrations with the presence of an sSMC enhanced in infertile groups when compared to the normal population; $0.125 \%$ and $0.044 \%$, respectively [Liehr and Weise, 2007].

There have been conflicting reports regarding the gender-specific rates of infertility in sSMC carriers, with initial results suggesting a male to female ratio of $7.5: 1$, though more recent studies have 
TABLE I. Previously Reported Postnatal Patients Who Presented With a Supernumerary Marker Chromosome That Developed by the Suspected McClintock Mechanism

\begin{tabular}{|c|c|c|c|c|c|c|}
\hline Case & Age/Sex & Karyotype & Mosaic & Neocentromere & Phenotype & Infertility \\
\hline $1^{\mathrm{a}}$ & $34 / \mathrm{M}$ & $47, X Y, \operatorname{del}[15)(q 11.1 \rightarrow q 21.1),+r(15)(q 11.1 \rightarrow q 21.1)$ & $\mathrm{N}$ & Y & $\begin{array}{l}\text { Marfan } \\
\text { syndrome }\end{array}$ & Y \\
\hline $2^{b}$ & $17 / M$ & 47,XY,del[4](q21.1 $\rightarrow$ q21.3),+r[4](q21.1 $\rightarrow$ q21.3) & Y & Y & $\begin{array}{l}\text { ID, hyper-IgE } \\
\text { syndrome }\end{array}$ & $?$ \\
\hline $3^{c}$ & $14 / \mathrm{M}$ & 47,XY,del[13)(q31 $\rightarrow$ q32), $+r(13)(q 31 \rightarrow q 32)$ & Y & Y & $\begin{array}{l}\text { ID, } \\
\text { dysmorphic } \\
\text { features }\end{array}$ & $?$ \\
\hline $4^{d}$ & $14 / F$ & 47,XY,del[2] $(p 21 \rightarrow p 11),+r(2)(p 21 \rightarrow p 11)$ & $\mathrm{N}$ & Y & $\begin{array}{l}\text { ID, } \\
\text { dysmorphic } \\
\text { features }\end{array}$ & N \\
\hline $5^{e}$ & ?/F & 47,XY,del(2)(q22 $\rightarrow$ q32.2),+r(2)(q22 $\rightarrow$ q32.2) & Y & ? & ID & ? \\
\hline $6^{f}$ & $23 / F$ & $47, X X, \operatorname{del}(3)(p 21.3 \rightarrow q 25),+r(3)(p 21.3 \rightarrow q 25)$ & $\mathrm{N}$ & Y & ID & $?$ \\
\hline $7^{8}$ & Adult $/ F$ & $47, X X, \operatorname{del}(4)(p 12 \rightarrow q 10),+r(4)(p 12 \rightarrow q 10)$ & Y & $\mathrm{N}$ & $\begin{array}{l}\text { External ear } \\
\text { anomalies }\end{array}$ & $\mathrm{N}$ \\
\hline $8^{\mathrm{h}}$ & $82 / F$ & $\begin{array}{l}47, X X, \operatorname{del}[17)(p t e r \rightarrow \text { cen::q11.2 or } q 12 \rightarrow q \text { ter }],+r[17) \\
\quad(\text { cen } \rightarrow q 11.2 \text { or } q 12)\end{array}$ & Y & $\mathrm{N}$ & NF1 & N \\
\hline $9^{i}$ & $19 / F$ & 47,XX,del(9)(pter $\rightarrow$ cen::q32 $\rightarrow$ qter $),+r(9)($ cen $\rightarrow$ q32) & Y & $\mathrm{N}$ & ID & ? \\
\hline $10^{j}$ & $23 / F$ & $47, X X$,del $(16)(p \operatorname{per} \rightarrow q 11.1:: q 13 \rightarrow q \operatorname{ter}),+r(16)(q 11.3 \rightarrow q 13)$ & Y & $\mathrm{N}$ & $\begin{array}{c}\text { ID, } \\
\text { dysmorphic } \\
\text { features }\end{array}$ & N \\
\hline $11^{\mathrm{k}}$ & $1 / F$ & $47, X, \operatorname{del}(X)($ pter $\rightarrow$ q21.1::p21 $\rightarrow$ pter $),+r(X)(p 21 \rightarrow q 11 \sim 12)$ & Y & $\mathrm{N}$ & ID, MCA & ? \\
\hline $12^{1}$ & $34 / F$ & $47, X X, \operatorname{del}(11)(p 11.1 \rightarrow p 15.1),+r(11)(11 p 11.1 \rightarrow p 15.1)$ & Y & $\mathrm{N}$ & Aniridia & N \\
\hline $13^{m}$ & $26 / \mathrm{M}$ & $47, X Y, \operatorname{del}[3](p 11 \rightarrow q 11],+r[3](p 11 \rightarrow q 11)$ & $\mathrm{N}$ & Y & Normal & $\mathrm{N}$ \\
\hline $14^{\mathrm{n}}$ & Adult/F & $\begin{array}{l}\text { 47,XX,del(6)(p11.2 p11.1 } \rightarrow \text { q12),+r(6) }(p 11.2 \sim p 11.1 \rightarrow \\
\text { q12) }\end{array}$ & Y & $\mathrm{N}$ & Normal & $\mathrm{N}$ \\
\hline $15^{\circ}$ & $41 / \mathrm{F}$ & $47, X X, \operatorname{del}(6)(q 11 \rightarrow q 13),+r(6)(q 11 \rightarrow q 13)$ & Y & $\mathrm{N}$ & Normal & $\mathrm{N}$ \\
\hline $16^{p}$ & Adult/F & 47,XX,del(11) (p11.12 $\rightarrow p 11.2),+r(11)(p 11.12 \rightarrow p 11.2)$ & Y & Y & Normal & $\mathrm{N}$ \\
\hline $17^{q}$ & Adult/F & $47, X X, \operatorname{del}(12)(p 13.1 \rightarrow q 10),+r(12)(p 13.1 \rightarrow q 10)$ & $\mathrm{N}$ & ? & $?$ & $\mathrm{~N}$ \\
\hline $18^{r}$ & $32 / F$ & $\begin{array}{l}\text { 47,XX,del(13)(pter } \rightarrow \text { q21.32:: q22.2 } \rightarrow \text { qter }),+r[13)[q 21.32 \rightarrow \\
\text { q22.2) }\end{array}$ & N & Y & Normal & $\begin{array}{c}\mathrm{N} ; 3 \\
\text { miscarriages }\end{array}$ \\
\hline $19^{\mathrm{s}}$ & $26 / F$ & 47,XX,del(17)(pter $\rightarrow$ p11.2::cen $\rightarrow q$ ter $)+r(17)(p 11.2 \rightarrow$ cen $)$ & Y & $?$ & Normal & $\mathrm{N}$ \\
\hline $20^{t}$ & $21 / F$ & $47, X X$,del $(19)(q 11.05 \rightarrow q 13.2),+r(19)(q 11.05 \rightarrow q 13.2)$ & $\mathrm{N}$ & $\mathrm{N}$ & Normal & $\mathrm{N}$ \\
\hline $21^{u}$ & $44 / F$ & $47, X X, \operatorname{del}(22)(q 11.1 \rightarrow q 11.2), r(22)(q 11.1 \rightarrow q 11.2)$ & Y & $\mathrm{N}$ & Normal & $\mathrm{N}$ \\
\hline $22^{v}$ & Adult/F & $47, X X, \operatorname{del}(22)(q 10 \rightarrow q 11.2)+r(22)(q 10 \rightarrow q 11.2)$ & $\mathrm{N}$ & N & Normal & $\mathrm{N}$ \\
\hline $23^{w}$ & Adult/M & 47,XY,del $(6)(p 22.3 \rightarrow q 10),+r(6)(p 22.3 \rightarrow q 10)$ & $\mathrm{N}$ & ? & Normal & Y \\
\hline $24^{x}$ & Adult/M & $\begin{array}{l}46, X Y, t(4 ; 15)(p 12 ; q 26.2), \operatorname{del}(6)(q 16.2 \rightarrow q 22.2),+r(6)(q 16.2 \rightarrow \\
q 22.2)\end{array}$ & $\mathrm{N}$ & Y & Normal & $\mathrm{N}$ \\
\hline $25^{y}$ & Adult/M & 47,XY,del(8) $(p 11.1 \rightarrow q 12.1),+r(8)(p 11.1 \rightarrow q 12.1)$ & Y & Y & Normal & $\mathrm{N}$ \\
\hline $26^{2}$ & $38 / \mathrm{M}$ & $47, Y, t(X ; 4)(q 23 ; q 13), \operatorname{del}(1)(p 32 \rightarrow p 36.1)+r(1)(p 32 \rightarrow p 36.1)$ & Y & Y & Normal & Y \\
\hline $27^{\text {aa }}$ & 29/M & $47, X Y, \operatorname{del}(13)(p \operatorname{pter} \rightarrow q 12.3:: q 22 \rightarrow q \operatorname{ter}),+r(13)(q 12.3 \rightarrow q 22)$ & Y & Y & Normal & Y \\
\hline $28^{\mathrm{bb}}$ & Adult/M & $47, X Y, \operatorname{del}(2)(p 12 \rightarrow p 11.1],+r(2)(p 12 \rightarrow p 11.1)$ & $\mathrm{N}$ & $\mathrm{N}$ & Normal & $\mathrm{N}$ \\
\hline
\end{tabular}

suggested a lower ratio though still favoring a male predominance [Liehr and Weise, 2007; Manvelyan et al., 2008; Liehr, 2014]. Review of Table I also supports a male predisposition towards infertility compared to females as only males have been reported with infertility in this cohort. It should be noted though that one female patient experienced three miscarriages, but eventually went on to have a normal pregnancy [Knegt et al., 2003]. Table I clearly represents a biased sampling as males represent only $34 \%$ (10/29) of the reported patients while females represent $66 \%$ (19/29). As some patients were ascertained through parental testing following the diagnosis of a child harboring an unbalanced chromosomal constitution, this falsely produces an elevated percentage of fertile females as infertility affects males more often. It has additionally been shown that male carriers of an sSMC derived from an acrocentric chromosome are more likely to present with impaired spermatogenesis, as was the case in our patient [Liehr, 2014]. Detailed sperm analysis of infertile sSMC carriers has been performed in individuals harboring the inv dup(15) sSMC and identified that $82.7 \%$ of sperm were 
unisomic, $17 \%$ were disomic, and $0.3 \%$ were trisomic suggesting there is a selection against the sSMC during meiosis [Eggermann et al., 2002]. Even with this selection, spermatogenesis appears to be significantly affected for unknown reasons. An additional important consideration is that a number of individuals affected with a McClintock mechanism-derived sSMC are severely neurocognitively impaired and do not have children, which should be differentiated from the infertility experienced by the patient described here.

Review of Table I shows that unlike other sSMC, those that arise via the suspected McClintock mechanism appear to not have a predilection towards involvement of acrocentric chromosomes. Roughly $40 \%$ of all sSMC involve chromosome 15 , with our patient representing the first to be identified with a McClintock mechanism-derived chromosome 15 aberration [http://ssmc-tl.com/ sSMC.html]. Interestingly, other acrocentric chromosomes appear to be involved, including chromosomes 13 and 22. It is possible that the chromosomal architecture of acrocentric chromosomes is not as susceptible to the McClintock mechanism as they are to the formation of other types of sSMC. The exact mechanism underlying this discrepancy is unknown at this time.

Interestingly, review of Table I also reveals the presence of a patient with an autosomal dominant Mendelian condition and an sSMC. Case 8 carried a clinical diagnosis of neurofibromatosis type 1 (NF1) based on the presence of axillary freckling and numerous pathologically confirmed neurofibromas [Andersen et al., 1990]. No NF 1 features were present in the patient's parents, seven siblings or daughter. She was found to have a chromosome 17-derived sSMC containing chromosomal material from a chromosome 17 interstitial deletion with the breakpoints around $17 \mathrm{q} 11.2$ or $17 \mathrm{q} 12$. The gene responsible for neurofibromatosis type $1, N F 1$, is on chromosome 17q12, the suspected breakpoint of the McClintock chromosome [Wallace et al., 1990]. Similar to our patient, whose ring chromosome contains at least part of the FBN1 gene, it was suspected that the NF1 allele on the SSMC was either truncated via the ring's formation or experienced silencing via its proximity to the centromere [Andersen et al., 1990]. Additional molecular analysis was never performed to confirm any of these hypotheses.

The genetic counseling for a patient or family harboring an sSMC can be complex based on the various chromosomal segregation possibilities and resultant phenotypic consequences. Patients need to be informed that this is a rare cytogenetic finding and therefore information is limited. Genetic counseling needs to define an sSMC and how chromosome imbalances can result and address the fertility issues, increased risk for pregnancy losses and the increased risk for children with genetic conditions, birth defects, and/or intellectual disability. In addition, reproductive options (assisted reproductive technologies, donor sperm/egg depending on patient's gender, adoption) and genetic testing options need to be discussed. In individuals with an apparently balanced karyotype due to the presence of a ring chromosome derived from a chromosomal deletion, empiric data suggests four possible resultant karyotypes in future offspring: (i) normal chromosomal constitution; (ii) inheritance of the deleted chromosome and the ring chromosome (apparently balanced); (iii) inheritance of only the deleted chromosome (monosomic); (iv) inheritance of the ring chromosome and the normal chromosome (trisomic). There are other unbalanced karyotypes that could arise due to other abnormal segregations that would result in greater imbalances and likely early miscarriage. In our patient's case, his abnormal interval also included the PraderWilli/Angelman syndrome region of chromosome 15 further complicating the counseling as potential chromosomal segregations also carried a risk for both of these conditions.

The patient presented here represents the first patient to be reported with an interstitial deletion of chromosome 15 with a resultant ring sSMC formed and stabilized by a neocentromere. The patient carried a clinical diagnosis of Marfan syndrome and it was determined that at least part of the FBN1 gene was on the sSMC. It is possible that the FNB1 allele itself or its regulatory elements were either disrupted through the process of ring formation or its proximity to the neocentromere resulted in the gene's silencing. This mechanism may also explain the clinical diagnosis of NF1 in a patient with a similar karyotypic abnormality [Andersen et al., 1990]. The abnormal chromosomal constitution was only identified as part of a work up for infertility, which is known to be associated with the presence of an sSMC. Our case continues to support the use of peripheral karyotype analysis in the evaluation of infertility particularly when a Mendelian condition is present.

\section{ACKNOWLEDGMENT}

We would like to thank the work of Thomas W. Glover for his cytogenetic assistance.

\section{REFERENCES}

Amor DJ, Voullaire L, Bentley K, Savarirayan R, Choo KHA. 2005. Mosaic monosomy of a neocentric ring chromosome maps brachyphalangy and growth hormone deficiency to 13q31. 1-13q32.3. Am J Med Genet Part A 133A:151-157.

Andersen LB, Tommerup N, Koch J. 1990. Formation of a minichromosome by excision of the proximal region of $17 \mathrm{q}$ in a patient with von Recklinghausen neurofibromatosis. Cytogenet Cell Genet 53:206-210.

Baldwin EL, May LF, Justice AN, Martin CL, Ledbetter DH. 2008 Mechanisms and consequences of small supernumerary marker chromosomes: From barbara McClintock to modern genetic-counseling issues. Am J Hum Genet 82:398-410.

Burnside RD, Ibrahim J, Flora C, Schwartz S, Tepperberg JH, Papenhausen PR. 2009 Interstitial Deletion of 8q in a girl from Unbalanced Segregation of a Paternal Deletion/ring Karyotype. ASHG abstract.

Chuang L, Wakui K, Sue W-C, Su M-H, Shaffer LG, Kuo P-L. 2005. Interstitial deletion $11(\mathrm{p} 11.12 \mathrm{p} 11.2)$ and analphoid marker formation results in inherited Potocki-Shaffer syndrome. Am J Med Genet Part A 133A:180-183.

Cui YX, Wei L, Xia XY, Fan XB, Shi YC, Yao B, Ge YF, Li XJ, Huang YF. 2011. Meiotic Pairing Error in an Infertile Male Bearing Reciprocal Deletion of Chromosome 13. J Androl 32:473-477.

Dietz HC, Cutting CR, Pyeritz RE, Maslen CL, Sakai LY, Corson GM, Puffenberger EG, Hamosh A, Nanthakumar EJ, Curristin SM, Stetten G, Meyers DA, Francomano CA. 1991. Marfan syndrome caused by a recurrent de novo missense mutation in the fibrillin gene. Nature 352:337-339.

Dietz HC, McIntosh I, Sakai LY, Corson GM, Chalberg SC, Pyeritz RE, Francomano CA. 1993. Four Novel FBN1 Mutations: Significance for mutant transcript level and EGF-like domain calcium binding in the pathogenesis of Marfan syndrome. Genomics 17:468-475. 
Donlon TA, Bangs CD, Hsieh C-L, Hahn J, Hsia YE, Gregory T. 1992. Interstitial deletion of chromosome $12 \mathrm{p}$ in a patient caused by maternal ring formation. Am J Hum Genet 51:A78.

Eggermann K, Mau UA, Bujdosó G, Koltai E, Engels H, Schubert R, Eggermann T, Raff R, Schwanitz G. 2002. Supernumerary marker chromosomes derived from chromosome 15: Analysis of 32 new cases. Clin Genet 62:89-93.

Eldadah ZA, Brenn T, Furthmayr H, Dietz HC. 1995. Expression of a mutant human fibrillin allele upon a normal human or murine genetic background recapitulates a Marfan cellular phenotype. J Clin Invest 95:874-880

Faivre L, Collod-Beroud G, Loeys BL, Child A, Binquet C, Gautier E, Callewaert B, Arbustini E, Mayer K, Arslan-Kirchner M, Kiotsekoglou A, Comeglio P, Marziliano N, Dietz HC, Halliday D, Beroud C, BonithonKopp C, Claustres M, Muti C, Plauchu H, Robinson PN, Adès LC, Biggin A, Benetts B, Brett M, Holman KJ, De Backer J, Coucke P, Francke U, De Paepe A, Jondeau G, Boileau C. 2007. Effect of mutation type and location on clinical outcome in 1,013 probands with Marfan syndrome or related phenotypes and FBN1 mutations: An international study. Am J Hum Genet 81:454-466.

Friedman JM, Harrod M. 1992. Complementary duplication and deletion of 17 (pcen $\rightarrow$ p11. 2): A family with a supernumerary chromosome comprised of an interstitially deleted segment. Am J Med Genet 44:37-40.

Grimbacher B, Dutra AS, Holland SM, Fischer RE. 1999. Analphoid marker chromosome in a patient with hyper-IgE syndrome, autism, and mild mental retardation. Genet Med 1:213-218.

Judge DP, Biery NJ, Keene DR, Geubtner J, Myers L, Huso DL, Sakai LY, Dietz HC. 2004. Evidence for a critical contribution of haploinsufficiency in the complex pathogenesis of Marfan syndrome. J Clin Invest 114:172-181.

Knegt AC, Li S, Engelen JJM, Bijlsma EK, Warburton PE. 2003. Prenatal diagnosis of a karyotypically normal pregnancy in a mother with a supernumerary neocentric $13 \mathrm{q} 21->13 \mathrm{q} 22$ chromosome and balancing reciprocal deletion. Prenat Diagn 23:215-220.

Krauss CM, Caldwell D, Atkins L. 1987. Interstitial deletion and ring chromosome derived from 16q. J Med Genet 24:308-312.

Lasan Trcic R, Hitrec V, Letica L, Cuk M. 2003. Small supernumerary marker chromosome derived from proximal p-arm of chromosome 2: Identification by fluorescent in situ hybridization. Croat Med J 44:477-479.

Liehr T. 2016. Small supernumerary marker chromosomes. http://ssmc-tl. com/mcclintock.html [accessed June 7, 2016].

Liehr T. 2014. Small supernumerary marker chromosomes detected in connection with infertility. Zhonghua Nan Ke Xue 20:771-780.

Liehr T, Klein E, Mrasek K, Kosyakova N, Guilherme RS, Aust N, Venner C, Weise A, Hamid AB. 2013. Clinical impact of somatic mosaicism in cases with small supernumerary marker chromosomes. Cytogenet Genome Res 139:158-163.

Liehr T, Weise A. 2007. Frequency of small supernumerary marker chromosomes in prenatal, newborn, developmentally retarded and infertility diagnostics. Int J Mol Med 19:719-731.

Loeys BL, Dietz HC, Braverman AC, Callewaert BL, De Backer J, Devereux RB, Hilhorst-Hofstee Y, Jondeau G, Faivre L, Milewicz DM, Pyeritz RE, Sponseller PD, Wordsworth P, De Paepe AM. 2010. The revised Ghent nosology for the Marfan syndrome. J Med Genet 47:476-485.

Mannens M, Hoovers J, Bleeker-Wagemakers EM. 1991. The distal region of 11p13 and associated genetic diseases. Genomics 11:284-293.

Manvelyan M, Riegel M, Santos M, Fuster C, Pellestor F, Mazaurik M-L, Schulze B, Polityko A, Tittelbach H, Reising-Ackermann G, Belitz B, Hehr U, Kelbova C, Volleth M, Gödde E, Anderson J, Küpferling P,
Köhler S, Duba H-C, Dufke A, Aktas D, Martin T, Schreyer I, Ewers E, Reich D, Mrasek K, Weise A, Liehr T. 2008. Thirty-two new cases with small supernumerary marker chromosomes detected in connection with fertility problems: Detailed molecular cytogenetic characterization and review of the literature. Int J Mol Med 21:705-714.

Maraschio P, Tupler R, Rossi E, Barbierato L, Uccellatore F, Rocchi M, Zuffardi O, Fraccaro M. 1996. A novel mechanism for the origin of supernumerary marker chromosomes. Hum Genet 97:382-386.

Marshall OJ, Chueh AC, Wong LH, Choo KHA. 2008. Neocentromeres: New insights into centromere structure, disease development, and karyotype evolution. Am J Hum Genet 82:261-282.

McClintock B. 1938. The production of homozygous deficient tissues with mutant characteristics by means of the aberrant mitotic behavior of ringshaped chromosomes. Genetics 23:315-376.

Nasiri F, Mahjoubi F, Soleimani S, Rahnama M, Mortezapour F, Manouchehri F, Razazian F, Zamanian M. 2007. Chromosomal findings in 8727 Iranian patients with mental retardation. Eur J Hum Genet 15:111.

Petit P, Fryns JP. 1997. Interstitial deletion 2p accompanied by marker chromosome formation of the deleted segment resulting in a stable acentric marker chromosome. Genet Couns 8:341-343.

Pfeiffer RA, Trautmann U, Hirmer-Stoll R. 1990. Interstitial deletion of chromosome $9 \mathrm{q}$ with coexistence of the deleted segment as a ring chromosome. A case report. Ann Genet 34:247-251.

Qin N, Bartley J, Wang JC, Warburton PE. 2007. A neocentromere derived from a supernumerary marker deleted from the long arm of chromosome 6. Cytogenet Genome Res 119:154-157.

Quack B, Van Roy N, Verschraegen-Spae MR. 1991. Interstitial deletion and ring chromosome derived from 19q. Proximal 19q trisomy phenotype. Ann Genet 35:241-244.

Reynolds A, Arora N, Donaldson A. 2004. An extremly rare, balanced chromosome rearrangement of chromosome 22 in a normal mother of a child with a supernumerary ring chromosome 22. J Med Gen 41:S58.

Slater HR, Nouri S, Earle E, Lo AW, Hale LG, Choo KH. 1999. Neocentromere formation in a stable ring 1p32-p36.1 chromosome. J Med Genet 36:914-918.

Stavropoulou C, Mignon C, Delobel B, Moncla A, Depetris D, Croquette MF, Mattei MG. 1998. Severe phenotype resulting from an active ring X chromosome in a female with a complex karyotype: Characterisation and replication study. J Med Genet 35:932-938.

Toutain J, Taine L, Morice-Picard F, Hallal H, Dai Z-Q, Arveiler B, Lacombe D, Horovitz J, Saura R. 2011. An unusual chromosome 22q11 deletion associated with an apparent complementary ring chromosome in a phenotypically normal woman. Eur J Med Genet 54:292-294.

Vlckova M, Trkova M, Zemanova Z, Hancarova M, Novotna D, Raskova D, Puchmajerova A, Drabova J, Zmitkova Z, Tan Y, Sedlacek Z. 2012. Mechanism and Genotype-Phenotype correlation of two proximal 6q deletions characterized using mBAND, FISH, Array CGH, and DNA sequencing. Cytogenet Genome Res 136:15-20.

Voullaire LE, Slater HR, Petrovic V, Choo KH. 1993. A functional marker centromere with no detectable alpha-satellite, satellite III, or CENP-B protein: Activation of a latent centromere? Am J Hum Genet 52: $1153-1163$.

Wallace MR, Marchuk DA, Andersen LB, Letcher R, Odeh HM, Saulino AM, Fountain JW, Brereton A, Nicholson J, Mitchell AL. 1990. Type 1 neurofibromatosis gene: Identification of a large transcript disrupted in three NF1 patients. Science 249:181-186.

Wandall A, Tranebjaerg L, Tommerup N. 1998. A neocentromere on human chromosome 3 without detectable alpha-satellite DNA forms morphologically normal kinetochores. Chromosoma 107:359-365. 